International Journal of Foundations of Computer Science Vol. 6 No. 4 (1995) 447-448

(C) World Scientific Publishing Company

\title{
AUTHOR INDEX \\ VOLUME 6 (1995)
}

Arvind, V., Köbler, J. and Schuler, R., On helping and interactive proof systems

$6(1995) 137-153$

Baeza-Yates, R.A. and Poblete, P.V., Higher-order analysis of 2-3 trees

Beeson, M., Using nonstandard analysis to ensure the correctness of symbolic computations

Besnard, P. and Kohlas, J., Evidence theory based on general consequence relations

Bloom, S.L. and Ésik, Z., Some equational laws of initiality in 2CCC's

Castellani, I., Observing distribution in processes: static and dynamic localities

Clementi, A. and Di Ianni, M., Optimum schedule problems in store and forward networks

Di Ianni, M., see Clementi, A.

Dubacq, J.-C., How to simulate Turing machines by invertible one-dimensional cellular automata

Ésik, Z., see Bloom, S.L.

Haralambides, J. and Tragoudas, S., Bipartitioning into overlapping sets

Hayashi, S. and Kobayashi, S., A new formalization of Feferman's system of functions and classes and its relation to frege structure

Hemaspaandra, L.A., Hoene, A., Naik, A.V., Ogihara, M., Selman, A.L., Thierauf, T. and Wang, J., Nondeterministically selective sets

Hintikka, J. and Sandu, G., What is the logic of parallel processing?

Hoene, A., see Hemaspaandra, L.A.

Iyer, S.P., see Peng, W.

Jain, S., An infinite class of functions identifiable using minimal programs in all Kolmogorov numberings

Kameyama, Y., A type-free theory of half-monotone inductive definitions

Kobayashi, S., see Hayashi, S.

Köbler, J., see Arvind, V.

Kohlas, J., see Besnard, P.

Mason, I. \& Talcott, C., Reasoning about object systems in VTLoE

Monserrat, M., Rosselló, F. and Torrens, J., When is a category of many-sorted partial algebras Cartesian-closed?

6 (1995) $1-10$

6 (1995) 299-338

6 (1995) 119-135

6 (1995) 95-118

6 (1995) 353-393

6 (1995) 155-168

6 (1995) 155-168

6 (1995) 395-402

6 (1995) 95-118

6 (1995) 67-88

6 (1995) 187-202

6 (1995) 403-416

6 (1995) 27-49

6 (1995) 403-416

6 (1995) 169-186

6 (1995) 89-94

6 (1995) 203-234

6 (1995) 187-202

6 (1995) 137-153

6 (1995) 119-135

6 (1995) 265-298

6 (1995) 51-66 
Musikaev, I.Kh. and Taitslin, M.A., Flat backtracking prolog for databases: a formal semantics, the computational complexity and the expressibility

Naik, A.V., see Hemaspaandra, L.A.

Ogihara, M., see Hemaspaandra, L.A.

Peng, W. and Iyer, S.P., A new type of pushdown automata on infinite trees

Poblete, P.V., see Baeza-Yates, R.A.

Raja, N. and Shyamasundar, R.K., The Quine-Bernays combinatory calculus

Rosselló, F., see Monserrat, M.

Sandu, G., see Hintikka, J.

Schuler, R., see Arvind, V.

Selman, A.L., see Hemaspaandra, L.A.

Shyamasundar, R.K., see Raja, N.

Slobodová, A., On the power of one-way globally deterministic synchronized alternating Turing machines and multihead automata

Smith, S.F., Hybrid partial-total type theory

Szwast, W., A note on the asymptotic probabilities of existential second-order minimal Gödel sentences with equality

Taitslin, M.A., see Musikaev, I.Kh.

Talcott, C., see Mason, I.

Thierauf, T., see Hemaspaandra, L.A.

Torrens, J., see Monserrat, M.

Tragoudas, S., see Haralambides, J.

Wang, J., see Hemaspaandra, L.A.

6 (1995) $11-26$

6 (1995) 403-416

6 (1995) $403-416$

6 (1995) 169-186

6 (1995) $1-10$

6 (1995) 417-430

6 (1995) 51-66

6 (1995) 27-49

6 (1995) $137-153$

6 (1995) 403-416

6 (1995) 417-430

6 (1995) 431-446

6 (1995) 235-263

6 (1995) 339-351

6 (1995) 11-26

6 (1995) 265-298

6 (1995) 403-416

6 (1995) 51-66

6 (1995) 67-88

6 (1995) 403-416 